OPEN ACCESS

Edited by:

Antonella Granieri,

University of Turin, Italy

Reviewed by:

Alice Avancini,

University of Verona, Italy

Nicholas Allan,

Ohio University, United States

*Correspondence:

Liping Zhao

zhaolp0818@csu.edu.cn

†These authors have contributed equally to this work

Specialty section

This article was submitted to

Public Mental Health,

a section of the journal

Frontiers in Psychiatry

Received: 22 May 2020 Accepted: 29 October 2020 Published: 24 November 2020

Citation:

Zhang $Y$, Chen $Y-p$, Wang J, Deng $Y$,

Peng D and Zhao L (2020) Anxiety

Status and Influencing Factors of Rural Residents in Hunan During the Coronavirus Disease 2019 Epidemic: A Web-Based Cross-Sectional Survey. Front. Psychiatry 11:564745. doi: 10.3389/fpsyt.2020.564745

\section{Anxiety Status and Influencing Factors of Rural Residents in Hunan During the Coronavirus Disease 2019 Epidemic: A Web-Based Cross-Sectional Survey}

\author{
Yi Zhang ${ }^{1,2 \dagger}$, Yi-ping Chen ${ }^{1 \dagger}$, Jianjian Wang ${ }^{2}$, Yanhong Deng ${ }^{2}$, Dezhen Peng ${ }^{2}$ and \\ Liping Zhao ${ }^{2 *}$ \\ ${ }^{1}$ Xiangya Nursing School, Central South University, Changsha, China, ${ }^{2}$ The Second Xiangya Hospital, Central South \\ University, Changsha, China
}

Objective: To explore the status quo of anxiety and its influencing factors among rural residents in Hunan Province during the coronavirus disease 2019 epidemic, and to provide an effective basis for prevention of and intervention for anxiety symptoms among rural residents.

Methods: Convenience sampling was used. An online questionnaire was distributed to Hunan rural residents through the questionnaire star platform from February 26-29, 2020. The general data and anxiety of Hunan rural residents were investigated, and the data were analyzed using SPSS 18.0.

Results: The mean Self-Rating Anxiety Scale score of 179 rural residents in Hunan was $40.93 \pm 9.36$. Based on the cutoff criteria, 32 residents had anxiety, including 26 with mild anxiety, five with moderate anxiety, and one with severe anxiety. The detection rate of anxiety was $17.88 \%$. Self-rated health status, level of concern about the epidemic, and self-rated impact of the epidemic on one's life were the factors influencing the anxiety score of rural residents in Hunan $(P<0.05)$.

Conclusion: During the coronavirus disease 2019 epidemic, the detection rate of anxiety in rural residents in Hunan was higher than that of the general population in China. The relevant departments should pay attention to the mental health of rural residents and implement targeted mental health prevention and intervention measures during the epidemic situation.

Keywords: corona virus disease 2019, rural residents, anxiety, Hunan (South China), COVID-19

\section{INTRODUCTION}

Since December 2019, coronavirus disease 2019 (COVID-19) epidemics have appeared around the world, starting in Wuhan, Hubei Province, China (1). As of October 4, 2020, the total number of confirmed cases worldwide was 34,804,348, with 1,030,738 cumulative associated deaths (2). The total number of confirmed cases in China was 85,470, with 4,634 deaths (3). It has had a considerable impact and caused psychological strain among Chinese people. 
Without doubt, the COVID-19 epidemic is a global public health problem that poses a serious threat to the global society, economy, and human health. The cognitivephenomenological-transactional model proposes that stress is generated through the specific relationship between the individual and the environment. The individual continually recognizes and evaluates stimuli in a stressful environment, and undergoes physical and psychological changes to adapt to the needs of the environment (4). Therefore, in the face of an epidemic, different groups of people will have different levels of anxiety, fear, helplessness, and even impulsive and irritating behaviors (5). Many studies have shown that mental health problems could occur in both medical staff and severe acute respiratory syndrome (SARS) survivors during the SARS epidemic (6-9). Previous studies of Middle East respiratory syndrome also reported similar results $(10,11)$. Researchers have conducted many surveys on the psychological status of people during the COVID-19 epidemic, but most of them have concentrated on special groups such as patients with COVID-19 $(12,13)$, medical staff $(14-16)$, or susceptible groups such as the elderly (17), children (18), and students (19). There are few studies on the psychological status of residents, especially rural residents. Rural areas have become extremely challenging for epidemic prevention and control because of various factors such as shortages of medical resources, insufficient public protection capabilities, and population migration caused by the return of migrant workers to their hometown (20). Previous research found that rural residents have poorer mental health compared to urban residents (21), and anxiety is one of the main problems affecting the mental health of rural residents (22). Hubei was the first and most severely affected province in the epidemic. As its neighboring province, Hunan Province is more likely to be exposed to suspected or infected cases than other regions, which increases residents' psychological pressure and anxiety. This study investigated the anxiety status of rural residents in Hunan during the COVID-19 epidemic and analyzed its influencing factors, intending to provide a scientific basis for effective psychological intervention for rural residents in Hunan.

\section{METHODS}

\section{Study Design and Sample}

A cross-sectional study was conducted among rural residents in rural areas of Hunan Province, China, from February 2629, 2020. The inclusion criteria were as follows: (a) living in the rural areas of Hunan Province during the COVID-19 epidemic; (b) aged 18 years or older; (c) proficient in WeChat and online questionnaires; and (d) were conscious and volunteered for the study. The exclusion criteria were as follows: participants with psychosis or severe mental disorders and inadequate communication ability.

Ethical approval was obtained from the ethics committee of Central South University (No: E202020) before data collection.

\section{Measures}

Socio-demographic characteristics were measured using a selfdesigned questionnaire, including gender, age, occupation, residence, marital status, relevant knowledge of COVID19 (understanding relevant knowledge or not, channels of knowledge acquisition), health status (temperature, self-rated health status, history of contact with Wuhan within the previous half month, and history of exposure to potentially infected people), level of concern about the epidemic, and self-rated impact of the epidemic on one's life.

Anxiety status was determined using the self-rating anxiety scale (SAS) (23). The scale consists of 20 items and aims to assess respondents' subjective symptoms. Each item was evaluated on a four-point Likert scale ranging from 1 ("little or none of the time") to 4 ("most of the time"), with higher scores indicating higher levels of anxiety. The Cronbach's alpha for the total scale was 0.864 , and it has good reliability and validity, and has been widely used in clinical research (24). According to the Chinese norm (25), the standard score has a cutoff value of 50, 50 to 59 represents mild anxiety, 60 to 68 represents moderate anxiety, and 69 points and above represents severe anxiety.

\section{Statistical Analysis}

\section{Sample Size}

We selected 18 possible influencing factors through a literature review. According to the principle that the sample size should be 5 to 10 times the number of independent variables, the estimated minimum sample size was 180 ; considering a likely attrition rate of $10 \%$ and sampling error, the final required sample size was 200 .

\section{Quality Control}

This survey used an online questionnaire. The questionnaire could only be submitted after it had been completed and each IP address could only answer once to avoid repeated answers. In addition, real-time background monitoring was performed to ensure data reliability. To prevent possible bias, a uniform guideline was used on the front page of the questionnaire to explain the completion requirements.

\section{Data Analysis}

Data analysis was performed using SPSS 18.0. Results are expressed as mean \pm standard deviation $(\mathrm{X} \pm \mathrm{S}$ ) or number (\%). First, descriptive analyses were conducted to describe the demographic characteristics, relevant knowledge of COVID19, and health status in rural residents in Hunan during the epidemic. Second, $t$-tests and one-way analysis of variance were used to analyze the anxiety levels of residents with different characteristics. Third, a $t$-test was used to compare the anxiety scores between rural residents in Hunan during the epidemic and different populations in different periods. Fourth, hierarchical regression analysis was performed to explore potential factors influencing residents' anxiety in Hunan during the COVID-19 epidemic. $P$-values $<0.05$ were considered statistically significant (2-sided tests).

\section{RESULTS}

We collected 200 questionnaires in the rural areas of 45 townships in 15 regions in Hunan Province. After checking each item one by one, a total of 21 questionnaires with high 
consistency of answers or answering time of $<150 \mathrm{~s}$ were excluded, and 179 valid questionnaires were obtained. The response rate of the questionnaire was $89.5 \%$.

As shown in Table 1, most participants were living with their spouse or family and only a few lived alone (5.6\%). Most participants had relevant knowledge of COVID-19 (93.9\%), and official platforms were their main channels for acquiring knowledge (76.5\%). Most participants expressed concern about this epidemic (93.9\%), and only 3.9\% of them self-rated that the epidemic did not affect their lives. Among them, 32 of the 179 participants (17.88\%) had anxiety; specifically, 26 participants had mild anxiety, five participants had moderate anxiety, and one participant had severe anxiety.

\section{Scores of Anxiety Levels of Rural Residents in Hunan During the COVID-19 Epidemic}

As shown in Table 2, the mean anxiety scores of rural residents in Hunan during the COVID-19 epidemic was $40.93 \pm 9.36$, which

TABLE 1 | Analysis of anxiety levels of people with different characteristics in Hunan rural residents during the epidemic of COVID-19.

\begin{tabular}{|c|c|c|c|c|c|c|c|}
\hline Variable & & $N$ & $\%$ & Mean (SD) & & $F / t$ & $\boldsymbol{P}$ \\
\hline Sex & $\begin{array}{l}\text { (1) Male } \\
\text { (2) Female }\end{array}$ & $\begin{array}{l}55 \\
124\end{array}$ & $\begin{array}{l}30.7 \\
69.3\end{array}$ & $\begin{array}{l}40.77 \pm 9.67 \\
40.99 \pm 9.26\end{array}$ & (1) $<$ (2) & 0.022 & 0.882 \\
\hline Age & $\begin{array}{l}\text { (1) } 18 \sim 29 y \\
\text { (2) } 30 \sim 39 y \\
\text { (3) } 40 \sim 49 y \\
\text { (4) } \geq 50 y\end{array}$ & $\begin{array}{l}63 \\
52 \\
36 \\
28\end{array}$ & $\begin{array}{l}35.2 \\
29.1 \\
20.1 \\
15.6\end{array}$ & $\begin{array}{c}40.00 \pm 9.14 \\
41.63 \pm 8.89 \\
41.04 \pm 10.83 \\
41.56 \pm 8.99\end{array}$ & $\begin{array}{l}\text { (1) }<\text { (2) } \\
\text { (3) }<\text { (4) }\end{array}$ & 0.346 & 0.792 \\
\hline Marital status & $\begin{array}{l}\text { (1) Married } \\
\text { (2) Unmarried }\end{array}$ & $\begin{array}{r}127 \\
52\end{array}$ & $\begin{array}{l}70.9 \\
29.1\end{array}$ & $\begin{array}{l}41.43 \pm 9.41 \\
39.71 \pm 9.21\end{array}$ & (2) $<$ (1) & 1.241 & 0.267 \\
\hline Educational level & $\begin{array}{l}\text { (1) Junior high school and } \\
\text { below } \\
\text { (2) High school } \\
\text { (3) Bachelor degree or above }\end{array}$ & $\begin{array}{l}69 \\
61 \\
49\end{array}$ & $\begin{array}{l}38.5 \\
34.1 \\
27.4\end{array}$ & $\begin{array}{l}41.88 \pm 8.93 \\
39.57 \pm 8.74 \\
41.28 \pm 10.62\end{array}$ & $\begin{array}{l}\text { (2) }<\text { (1) } \\
\text { (3) }<\text { (1) }\end{array}$ & 1.036 & 0.357 \\
\hline Residential status & $\begin{array}{l}\text { (1) Living alone } \\
\text { (2) Living with spouse or } \\
\text { family } \\
\text { (3) Living with friends or } \\
\text { others }\end{array}$ & $\begin{array}{c}6 \\
169 \\
4\end{array}$ & $\begin{array}{c}3.4 \\
94.4 \\
2.2\end{array}$ & $\begin{array}{l}39.38 \pm 8.83 \\
41.04 \pm 9.43 \\
38.75 \pm 8.60\end{array}$ & $\begin{array}{l}\text { (3) }<\text { (2) } \\
\text { (2) }<\text { (1) }\end{array}$ & 0.200 & 0.819 \\
\hline $\begin{array}{l}\text { Know relevant knowledge of } \\
\text { COVID-19 }\end{array}$ & $\begin{array}{l}\text { (1) Yes } \\
\text { (2) No }\end{array}$ & $\begin{array}{c}168 \\
11\end{array}$ & $\begin{array}{c}93.9 \\
6.1\end{array}$ & $\begin{array}{l}41.02 \pm 9.53 \\
39.55 \pm 9.36\end{array}$ & (2) $<$ (1) & 0.255 & 0.614 \\
\hline $\begin{array}{l}\text { Main channels for acquiring } \\
\text { relevant knowledge }\end{array}$ & $\begin{array}{l}\text { (1) Official platform } \\
\text { (2) Unofficial platforms } \\
\text { (3) Others } \\
\text { (4) No knowledge of relevant } \\
\text { information }\end{array}$ & $\begin{array}{c}137 \\
32 \\
9 \\
1\end{array}$ & $\begin{array}{c}76.5 \\
17.9 \\
5.0 \\
0.6\end{array}$ & $\begin{array}{c}40.60 \pm 9.41 \\
41.91 \pm 9.77 \\
40.69 \pm 6.41 \\
56.25\end{array}$ & $\begin{array}{l}\text { (1) }<\text { (2) } \\
\text { (3) }<\text { (2) }\end{array}$ & 1.070 & 0.363 \\
\hline $\begin{array}{l}\text { Contacted with the people } \\
\text { have been to Wuhan within } \\
\text { half a month }\end{array}$ & $\begin{array}{l}\text { (1) Yes } \\
\text { (2) No }\end{array}$ & $\begin{array}{c}10 \\
169\end{array}$ & $\begin{array}{l}5.6 \\
94.4\end{array}$ & $\begin{array}{r}44.00 \pm 10.01 \\
40.75 \pm 9.32\end{array}$ & (2) $<$ (1) & 1.141 & 0.287 \\
\hline $\begin{array}{l}\text { Going out or gathering } \\
\text { within half a month }\end{array}$ & $\begin{array}{l}\text { (1) Yes } \\
\text { (2) No }\end{array}$ & $\begin{array}{l}38 \\
141\end{array}$ & $\begin{array}{l}21.2 \\
78.8\end{array}$ & $\begin{array}{l}42.34 \pm 9.70 \\
40.55 \pm 9.26\end{array}$ & (2) $<$ (1) & 1.090 & 0.298 \\
\hline $\begin{array}{l}\text { Wearing a mask when going } \\
\text { out }\end{array}$ & $\begin{array}{l}\text { (1) Yes } \\
\text { (2) No }\end{array}$ & $\begin{array}{c}171 \\
8\end{array}$ & $\begin{array}{c}95.5 \\
4.5\end{array}$ & $\begin{array}{l}40.88 \pm 947 \\
41.88 \pm 7.13\end{array}$ & (1) < (2) & 0.085 & 0.771 \\
\hline Adequate masks at home & $\begin{array}{l}\text { (1) Yes } \\
\text { (2) No }\end{array}$ & $\begin{array}{l}99 \\
80\end{array}$ & $\begin{array}{l}55.3 \\
44.7\end{array}$ & $\begin{array}{l}40.44 \pm 8.90 \\
41.53 \pm 9.92\end{array}$ & (1) < (2) & 0.598 & 0.440 \\
\hline Self-rated of health status & $\begin{array}{l}\text { (1) Very good } \\
\text { (2) Good } \\
\text { (3) Fair } \\
\text { (4) Poor }\end{array}$ & $\begin{array}{c}135 \\
34 \\
8 \\
2\end{array}$ & $\begin{array}{l}75.4 \\
19.0 \\
4.5 \\
1.1\end{array}$ & $\begin{array}{c}39.73 \pm 8.65 \\
43.16 \pm 10.27 \\
48.90 \pm 11.72 \\
51.88 \pm 2.65\end{array}$ & $\begin{array}{l}\text { (1) }<\text { (2) } \\
\text { (2) }<(3)^{*} \\
(3)<(4)^{*}\end{array}$ & 4.477 & $0.005^{*}$ \\
\hline $\begin{array}{l}\text { Level of concern about the } \\
\text { epidemic }\end{array}$ & $\begin{array}{l}\text { (1) Not at all concerned } \\
\text { (2) Had some concerns } \\
\text { (3) Very worried }\end{array}$ & $\begin{array}{c}11 \\
100 \\
68\end{array}$ & $\begin{array}{c}6.1 \\
55.9 \\
38.0\end{array}$ & $\begin{array}{l}35.34 \pm 7.83 \\
40.29 \pm 9.02 \\
42.78 \pm 9.71\end{array}$ & $\begin{array}{l}(1)<(2)^{*} \\
(2)<(3)^{*}\end{array}$ & 3.622 & 0.029 * \\
\hline $\begin{array}{l}\text { Self-rated of the impact of } \\
\text { the epidemic on life }\end{array}$ & $\begin{array}{l}\text { (1) Not affected } \\
\text { (2) A little bit affected } \\
\text { (3) Very affected }\end{array}$ & $\begin{array}{c}7 \\
88 \\
84\end{array}$ & $\begin{array}{c}3.9 \\
49.2 \\
46.9\end{array}$ & $\begin{array}{l}35.54 \pm 9.10 \\
39.72 \pm 8.22 \\
40.93 \pm 9.36\end{array}$ & $\begin{array}{l}(1)<(2)^{*} \\
(2)<(3)^{*}\end{array}$ & 3.408 & 0.035 * \\
\hline
\end{tabular}

${ }^{*} P<0.05$. 
was higher than the rural residents' anxiety scores during the non-epidemic period ( $t=14.820, P<0.001$ ), which was also higher than the anxiety scores of healthy Chinese individuals during the non-epidemic period $(t=55.098, P<0.001)$. However, compared with the anxiety scores of rural residents across China during the epidemic, rural residents in Hunan had lower anxiety scores $(t=-4.375, P<0.001)$. In terms of anxiety detection rate, only the difference between rural residents in Hunan during the epidemic and healthy people before the epidemic was statistically significant $\left(\chi^{2}=6.644, P=0.010\right)$.

\section{Factors Influencing Rural Resident' Anxiety in Hunan During the COVID-19 Epidemic}

The results showed that self-rated health status, level of concern about the epidemic, and self-rated impact of the epidemic on one's life had statistically significant effects on anxiety scores $(P$ $<0.05$, as shown in Table $\mathbf{1}$ ).

\section{Hierarchical Regression Analysis of the Influencing Factors of Rural Residents' Anxiety Score in Hunan During the COVID-19 Epidemic}

Hierarchical regression analysis was used to analyze whether the gradual addition of self-rated health status, level of concern about the epidemic, and self-rated impact of the epidemic on one's life could improve the model's prediction level of the standard anxiety score.

The final model included three variables: self-rated health status, level of concern about the epidemic, and self-rated impact of the epidemic on one's life, which was statistically significant,
$R^{2}=0.113, F(3,175)=7.465(P<0.001)$, adjusted $R^{2}=0.098$, which explained $11.3 \%$ of the total variation in the anxiety scores of rural residents in Hunan during the COVID-19 epidemic.

Self-rated health status was added into Model 1 and the $R^{2}$ value of Model 1 was $0.070, F(1,171)=13.304(P<0.001)$. After adding level of concern about the epidemic, the $R^{2}$ value of Model 2 increased by $0.035, F(1,176)=6.890(P<0.01)$, which was statistically significant. Based on Model 2 and adding self-rated impact of the epidemic on one's life, the $R^{2}$ value of Model 3 increased by $0.009, F(1,175)=1.678(P=0.197>$ $0.05)$, which was not statistically significant. The specific results are shown in Table 3.

\section{DISCUSSION}

\section{Anxiety Status of Rural Residents in Hunan During the COVID-19 Epidemic}

The results of this survey show that the anxiety score of rural residents in Hunan during the COVID-19 epidemic was higher than that of healthy Chinese (26) and rural residents across China (27) during the non-epidemic period. Our research found that the detection rate of anxiety among rural residents in Hunan was $17.88 \%$, while one Turkish study reported that the detection rate of anxiety in people was $45.1 \%$ (28) while a study on American adults found a rate of $38.41 \%$ (29). The reason for this difference may be that our research was carried out in February, while their research was mainly carried out in April 2020. At this time, COVID-19 was spreading around the world and the epidemic was worsening. Due to the strong contagion, long incubation period, wide spread, and rapid progress of COVID-19, the epidemic seriously threatens

TABLE 2 | Comparison of the anxiety level of rural residents in Hunan during the epidemic and different populations in different periods.

\begin{tabular}{|c|c|c|c|c|c|c|c|c|}
\hline & & $\begin{array}{l}\text { Total } \\
\text { number } \\
\text { of } \\
\text { sample }\end{array}$ & Mean (SD) & $t$ & $P$-value & $\begin{array}{c}\text { Number of } \\
\text { anxiety } \\
\text { detected (\%) }\end{array}$ & $\chi^{2}$ & $P$-value \\
\hline \multirow{3}{*}{$\begin{array}{l}\text { Anxiety level of residents in } \\
\text { different regions during the } \\
\text { epidemic }\end{array}$} & & & & -4.375 & $<0.001$ & & 3.708 & 0.054 \\
\hline & $\begin{array}{l}\text { Rural residents in Hunan } \\
\text { Province }\end{array}$ & 179 & $40.93 \pm 9.30$ & & & $32(17.9)$ & & \\
\hline & Rural residents across China & 1,029 & $43.99 \pm 8.55$ & & & 398(38.7) & & \\
\hline \multirow{3}{*}{$\begin{array}{l}\text { Anxiety level of rural } \\
\text { residents in different periods }\end{array}$} & & & & 14.820 & $<0.001$ & & 0.730 & 0.393 \\
\hline & During the epidemic & 179 & $40.93 \pm 9.30$ & & & $32(17.9)$ & & \\
\hline & During non-epidemic period & 778 & $30.56 \pm 5.94$ & & & 119(15.3) & & \\
\hline \multirow{3}{*}{$\begin{array}{l}\text { Anxiety level of rural } \\
\text { residents in Hunan Province } \\
\text { during the epidemic and } \\
\text { healthy people during } \\
\text { non-epidemic period }\end{array}$} & & & & 55.098 & $<0.001$ & & 6.644 & 0.010 \\
\hline & $\begin{array}{l}\text { Rural residents in Hunan } \\
\text { province during the epidemic }\end{array}$ & 179 & $40.93 \pm 9.30$ & & & $32(17.9)$ & & \\
\hline & $\begin{array}{l}\text { Healthy people during } \\
\text { non-epidemic period }\end{array}$ & 1,158 & $29.78 \pm 10.07$ & & & $129(11.1)$ & & \\
\hline
\end{tabular}


TABLE 3 | Hierarchical regression analysis of the influencing factors of rural residents' anxiety score in Hunan during the epidemic of COVID-19.

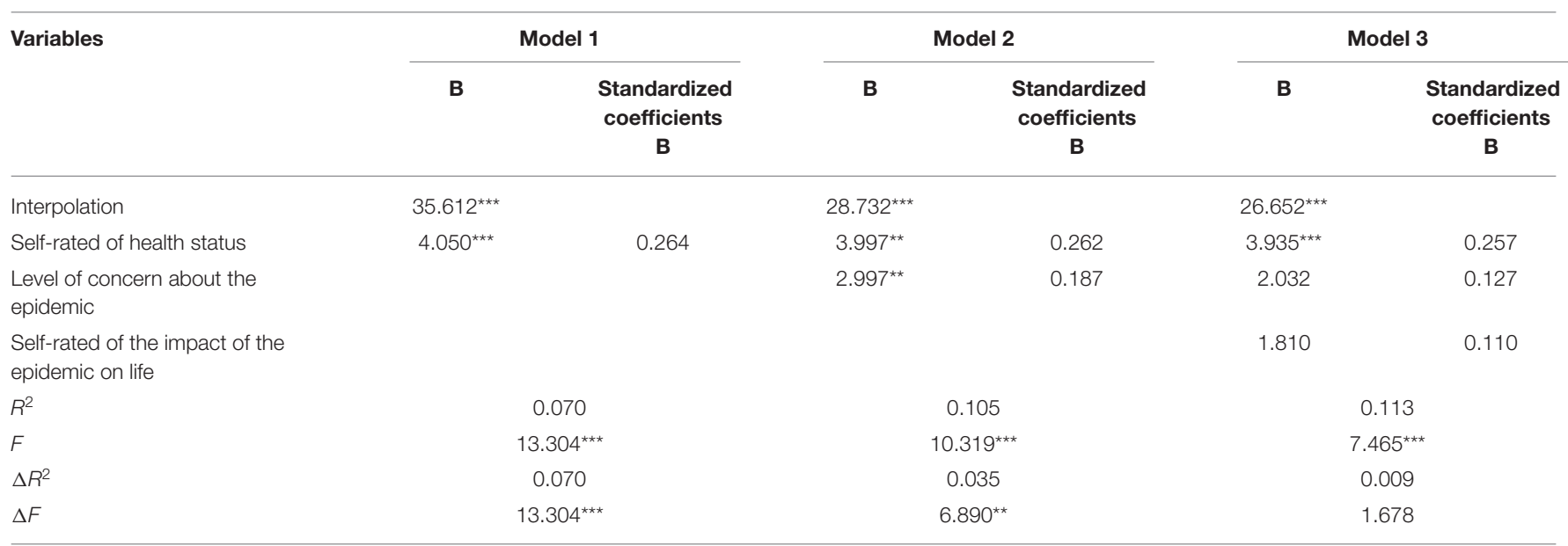

$N=179,{ }^{\star *} P<0.01,{ }^{\star \star \star} P<0.001$.

people's health and safety, and people will inevitably experience negative emotions such as anxiety and fear when facing the epidemic (30). However, it is worth mentioning that because of the specific geographical location of Hunan (near Hubei Province, the province where the epidemic first broke out), before the survey, researchers predicted that rural residents in Hunan Province may have higher levels of anxiety, but our results show that during the COVID-19 epidemic, rural residents' anxiety scores in Hunan were lower than national rural residents' anxiety scores (43.99 \pm 8.55$)$, as investigated by Wang (31). This may be related to the fact that the Chinese government immediately locked down Wuhan and the entire Hubei Province after the outbreak of the epidemic to contain the pandemic, so that the epidemic did not break out in large areas in Hunan Province, and the growth rate of the epidemic gradually decreased; thus, most residents in the vicinity of the epidemic became increasingly confident.

\section{Factors Influencing the Anxiety of Rural Residents in Hunan During the COVID-19 Epidemic \\ Self-Rated Health Status}

Residents who considered themselves to be in poor health had higher anxiety scores than residents who considered their health to be good, and their average anxiety score reached the anxiety cutoff. Metacognition theory posits that self-centered consciousness activities are positive feedback and adjustments to consciousness (32). Therefore, residents who believe they are in good health will be confident in resisting attacks of COVID-19, while residents who believe they are in poor health may think they will be more susceptible to the virus and if they are infected, have no confidence in defeating it, so their anxiety scores would be higher than those who think they are in good health. Studies $(33,34)$ have shown that emotional therapy has a positive effect on easing the public's negative emotions during the epidemic; therefore, self-positive suggestion may relieve residents' anxiety.

\section{Level of Concern About the Epidemic}

The higher their level of concern about the epidemic, the higher the residents' anxiety score. Studies by Li (35) and Zhang (24) also showed that the degree of concern about the epidemic is a factor influencing anxiety among different groups of people during the COVID-19 epidemic. Several factors are likely to induce anxiety among residents, including the number of confirmed cases and deaths from COVID-19 that continue to rise daily, lack of knowledge of the disease, surrounding people who may have been infected with the virus, and the lack of anti-coronavirus specific drugs (36), among other reasons. Cai (37) believed that during the epidemic, people only know what COVID-19 is but do not know how to control it, which is not sufficient to reduce its effects on their psychological problems. The key is to know how to prevent and control COVID-19. Leung et al. (38) found that publicizing measures for disease prevention and eliminating the spread of rumors can reduce public anxiety. The results of this survey showed that most people acquired relevant knowledge of COVID-19 through an official platform. Therefore, it is necessary to strengthen the dissemination of disease information and prevention measures on official platforms.

\section{Self-Rated Impact of the Epidemic on One's Life}

The greater their self-rated impact of the epidemic on one's life, the higher the residents' anxiety scores. The population density in rural areas is smaller than that in cities or towns, and houses are mostly single-family houses, so rural residents can have a wide range of activities in a relatively safe and isolated environment. Some rural residents usually work in fields or farms and rarely go to densely populated areas, so they feel that the epidemic has little impact on their lives and have low anxiety scores. However, some rural residents need to go to cities to earn a living or need to be in contact with others at work; during the epidemic, their financial and living pressures have greatly increased due to work restrictions, so their anxiety scores are high. For these individuals, it is necessary to actively solve practical problems such as the delayed resumption of work and limited social activities (39). 


\section{LIMITATIONS}

Due to the difficulties and limitations in collecting data during the epidemic, random sampling was not conducted in this survey, and the nature of the sample may limit the generalizability of the results. In addition, due to the use of online questionnaires, the survey only included people who can operate WeChat proficiently. Elderly and rural residents who do not use WeChat were not included. Further longitudinal studies should be conducted to better investigate the psychological status of and interventions for rural residents more deeply.

\section{CONCLUSION}

COVID-19 is having a huge impact on the life and the psychology of rural residents in Hunan Province, China. During the epidemic, their anxiety rate was high. This was a particular phenomenon of residents in a specific period; we need to pay enough attention to it and seek positive solutions to deal with it ingeniously. The results showed that self-rated health status, level of concern about the epidemic, and self-rated impact of the epidemic on one's life are the main factors that affect how anxious rural residents are. It is necessary to increase publicity about COVID-19 prevention measures and provide positive psychological guidance to alleviate rural residents' anxiety. Timely announcements about the epidemic, vigorous publicity about epidemic prevention measures, and the support of all sectors of society will give people around the world greater confidence and strength to overcome the epidemic (40).

\section{REFERENCES}

1. Chen N, Zhou M, Dong X, Qu J, Zhang L. Epidemiological and clinical characteristics of 99 cases of 2019 novel coronavirus pneumonia in Wuhan, China: a descriptive study. Lancet. (2020) 395:507-13. doi: 10.1016/S0140-6736(20)30211-7

2. World Health Organization. Novel coronavirus (2019- $n$ CoV): situation report. World Health Organization (2020). Available online at: https://www.who.i nt/emergencies/diseases/novel-coronavirus-2019/situation-reports/ (accessed October 4, 2020).

3. National Health Committee of the People's Republic of China. Update on the Pneumonia Epidemic of Novel Coronavirus Infections as of October 4, 2020. Available online at: http://www.nhc.gov.cn/xcs/yqtb/202010/9fac34dfe1434b 1d8d30909bdef4e7f9.shtml (accessed October 4, 2020).

4. Wei YH, Tang SQ. Several major theoretical models of stress and their evaluation. Psychol Sci. (1998) 5:441-4. doi: 10.16719/ j.cnki.1671-6981.1998.05.015

5. Lu L, Wang GH. Universal Mental Health Example Manual for New Coronavirus Pneumonia. Bejing: Peking University Medical Press (2020).

6. Wu KK, Chan SK, Ma TM. Posttraumatic stress, anxiety, and depression in survivors of severe acute respiratory syndrome (SARS). J Trauma Stress. (2005) 18:39-42. doi: 10.1002/jts.20004

7. Mcalonan G, Lee A, Cheung V, Cheung C, Tsang K, Sham P, et al. Immediate and sustained psychological impact of an emerging infectious disease outbreak on health care workers. Can J Psychiatry. (2007) 52:241-7. doi: 10.1177/070674370705200406

\section{DATA AVAILABILITY STATEMENT}

The raw data supporting the conclusions of this article will be made available by the authors, without undue reservation.

\section{ETHICS STATEMENT}

The studies involving human participants were reviewed and approved by The Ethics Committee of the Xiangya Nursing School, Central South University. Written informed consent for participation was not required for this study in accordance with the national legislation and the institutional requirements.

\section{AUTHOR CONTRIBUTIONS}

$\mathrm{YZ}$ and Y-pC were the primary investigator of the study, did statistical analysis and wrote this paper. JW and YD helped conduct the study and revised the manuscript. DP and LZ helped supervised the survey and checked the data. All authors contributed to and approved the final manuscript.

\section{FUNDING}

This study is supported by the Philosophy and Social Science Foundation of Hunan province, China (Grant No. 18YBA444).

\section{ACKNOWLEDGMENTS}

The authors wish to thank all those in the survey who helped to recruit participants. Appreciation is extended to all the researchers for their work on this study.

8. Lu YC, Shu BC, Chang YY, Lung FW. The mental health of hospital workers dealing with severe acute respiratory syndrome. Psychother Psychosom. (2006) 75:370-5. doi: 10.1159/000095443

9. Lee AM, Wong JG, Mcalonan GM, Cheung V, Cheung C, Sham PC, et al. Stress and psychological distress among SARS survivors 1 year after the outbreak. Can J Psychiatry. (2007) 52:233-40. doi: 10.1177/070674370705200405

10. Lee SM, Kang WS, Cho AR, Kim T, Park JK. Psychological impact of the 2015 MERS outbreak on hospital workers and quarantined hemodialysis patients. Compr Psychiat. (2018) 87:123-7. doi: 10.1016/j.comppsych.2018.10.003

11. Imran, Khalid, Tabindeh J, Mohammed R, Qabajah, Aletta G, et al. Healthcare workers emotions, perceived stressors and coping strategies during a MERS-CoV outbreak. Clin med res. (2016)14:7-14. doi: 10.3121/ cmr.2016.1303

12. Ng D, Chan F, Barry TJ, Lam C, Lam WWT. Psychological distress during the 2019 coronavirus disease (COVID) pandemic among cancer survivors and healthy controls. Psycho-Oncol. (2020) 29:1380-3. doi: 10.1002/ pon. 5437

13. Nie XD, Wang Q, Wang MN, Zhao S, Chen H. Anxiety and depression and its correlates in patients with coronavirus disease 2019 in Wuhan. Int J Psychiat Clin. (2020) 1-6. doi: 10.1080/13651501.2020.1791345

14. Labrague LJ, Santos JAAD. COVID-19 anxiety among front-line nurses: predictive role of organisational support, personal resilience and social support. J Nurs Manage. (2020)28:1653-61. doi: 10.1111/jonm.13121

15. Nanjundaswamy MH, Pathak H, Chaturvedi SK. Perceived stress and anxiety during COVID-19 among psychiatry trainees. Asian J Psychiatr. (2020) 54:102282. doi: 10.1016/j.ajp.2020.102282 
16. Zhang WR, Wang K, Yin L, Zhao WF, Wang HX. Mental health and psychosocial problems of medical health workers during the COVID-19 epidemic in China. Psychother Psychosom. (2020) 89:1-9. doi: 10.1159/000507639

17. Bergman YS, Fridel SC, Shrira A, Bodner E, Palgi Y. COVID-19 health worries and anxiety symptoms among older adults: the moderating role of ageism. Int Psychogeriatr. (2020) 17:1-5. doi: 10.1017/S1041610220001258

18. Abawi O, Welling MS, van den Eynde E, van Rossum EFC, Halberstadt J, van den Akker ELT, et al. COVID-19 related anxiety in children and adolescents with severe obesity: a mixed-methods study. Clin obes. (2020) e12412. doi: 10.1111/cob.12412

19. Cao W, Fang Z, Hou G, Han M, Zheng J. The psychological impact of the COVID-19 epidemic on college students in China. Psychiat Res. (2020) 287:112934. doi: 10.1016/j.psychres.2020.112934

20. Zhang YN, Bao W. Study on emergency management in rural areas under major public health emergencies: a case study of coronavirus pneumonia. Anhui Agric Sci Bull. (2020) 26:7-8. doi: 10.16377/j.cnki.issn1007-7731.2020.15.004

21. Wang L, Zhang X, Gao J. Status and influencing factors of mental health among adult residents in China. Chin J Publ Heal. (2019) 35: 579-82. doi: $10.11847 /$ zgggws1121876

22. Jin YL, Yao YS, Wen YF, Zhang L, An Z, Ye DQ. Correlation study on depression, anxiety and negative life events among rural citizens. Modern Prev Med. (2009) 36:4474-6.

23. Zung WW. A rating instrument for anxiety disorders. Psychosomatics. (1971) 12:371-9.

24. Zhang C, Wu JP, Li JN, Guo XD, Liu SH, Zeng YM. Analysis of psychological status of patients with diabetes mellitus during the epidemic period of novel coronavirus pneumonia. Chinese Gen Pract Nurs. (2020) 18:965-1012. doi: 10.12104/j.issn.1674-4748.2020.08.065

25. XY D. Manual of commonly used psychological assessment scales. Beijing: People's Military Medical Press. (2010). p. 310-3.

26. Wang XD, Wang XL, Ma H. Mental health rating scale manual (updated). Beijing: Chinese Mental Health J. (1999). 235-7.

27. Guo WH, Ding H. Prevalence and influencing factors of anxiety among rural residents in Anhui province. Chin J Dis Control Prev. (2016) 20:101-103. doi: 10.16462/j.cnki.zhjbkz.2016.01.026

28. Zdin SU, Zdin KB. Levels and predictors of anxiety, depression and health anxiety during COVID-19 pandemic in Turkish society: the importance of gender. Int J Soc Psychiatr. (2020) 66:504-11. doi: 10.1177/0020764020927051

29. Gallagher MW, Zvolensky MJ, Long LJ, Rogers AH, Garey L. The impact of Covid-19 experiences and associated stress on anxiety, depression, and functional impairment in American adults. Cognitive Ther Res. (2020) 44:1-9. doi: 10.1007/s10608-020-10143-y

30. Wang C, Wang X. Prevalence, nosocomial infection and psychological prevention of novel coronavirus infection. Chinese Gen Nurs. (2020) 18:30910. doi: $10.12104 /$ j.issn.1674-4748
31. Wang YW, Wang CD, Liao ZX, Zhang XY, Zhao MY. A comparative analysis of anxiety and depression level among people and epidemic characteristics between COVID-19 and SARS. Life Sci Res. (2020) 24:180-6. doi: 10.16605/j.cnki.1007-7847.2020.03.002

32. Wen LP. Exploration of the relationship between metacognition and mental health. J Heilongjiang Vocational Inst Ecol Eng. (2019) 32:112-4. doi: 10.3969/j.issn.1674-6341

33. Liu LY, Yang JW, Han M, Wang Q, Feng B, Zhang JM. Novel coronavirus pneumonia epidemic psychological crisis intervention technology from the perspective of TCM. Modernization Tradition Chinese Med Materia Medica-World Sci Technol. (2020) 22:303-5. doi: 10.11842/wst.20200 219002

34. Yu F, Li J, Ma H. Talking about COVID-19. Acta Chinese Med. (2020) 25:469-472. doi: 10.16368/j.issn.1674-8999

35. Li SW, Wang Y, Yang YY, Lei XM, Ynag YF. Analysis of influencing factors of anxiety and emotional disorder in children and adolescents during home isolation during the novel coronavirus pneumonia epidemic. Chinese J Child Health Care. (2020) 28:407-10. doi: 10.11852/zgetbjzz2020-0169

36. Su S, Li XC, Hao H, Wang XY, Zhang MM, Geng H, et al. Advances in research on SARS-CoV-2. J Xi'an Jiaotong Univ Med Sci. (2020) 41:479-82. doi: 10.7652/jdyxb202004002

37. Cai HL, Zhu YX, Lei LB, Pan HC, Zhu LW, Li J, et al. Novel coronavirus pneumonia epidemic-related knowledge, behaviours and psychological status among college students and their family members and friends: an internet-based cross-sectional survey. Chinese J Pub Heal. (2020) 36:152-5. doi: 10.11847 /zgggws1128106

38. Leung M G. The impact of community psychological responses on outbreak control for severe acute respiratory syndrome in Hong Kong. J Epidemiol Community Health. (2003) 57:857-63. doi: 10.1136/jech.57.11.857

39. Chen JX, Shi JY, Zhao XD. Consideration of effective psychological aid in the epidemic of COVID-19. J Tongji Univ. (2020) 41:5-8. doi: 10.16118/j.1008-0392.2020.01.002

40. Zhu JP. Dissemination of epidemic information should be dominated by audience needs-observation of domestic public opinion field after the outbreak of novel coronavirus pneumonia. The Press. (2020) 2:6-8.

Conflict of Interest: The authors declare that the research was conducted in the absence of any commercial or financial relationships that could be construed as a potential conflict of interest.

Copyright (C) 2020 Zhang, Chen, Wang, Deng, Peng and Zhao. This is an open-access article distributed under the terms of the Creative Commons Attribution License (CC $B Y)$. The use, distribution or reproduction in other forums is permitted, provided the original author(s) and the copyright owner(s) are credited and that the original publication in this journal is cited, in accordance with accepted academic practice. No use, distribution or reproduction is permitted which does not comply with these terms. 